\title{
Mobile advertising and its impact on message acceptance and purchase Intention
}

\author{
Mohammed Saleh Salem \\ Sulaiman Althuwaini \\ Business Studies Department, \\ Arab Open University, Saudi Arabia \\ Sufyan Habib \\ Saudi Electronic University, Saudi Arabia
}

\section{Keywords}

Mobile advertising, consumer acceptance, consumer permission, purchase intention, Saudi Arabia.

\begin{abstract}
Advertising is experiencing rapid technological changes that have led to digitalization of media, consequently resulting in the emergence of new media types, such as mobile phones. This has facilitated the easy spread of advertisements among consumers and allowed interaction with them in an easier manner. However, to fully utilize the potential of the mobile phone as an advertising channel, marketers must understand its unique and relevant characteristics and the different approaches that consumers use to interact with this channel. The purpose of this study is to examine the relationship between message relevance, information value, message receiving time, and consumers' permission to receive advertising messages as independent variables and consumers' acceptance of mobile advertising and subsequent effect on purchase intention of promoted products or services using mobile advertising. Based on the information obtained from 205 respondents of Saudi Arabia, the present study attempts to examine the relationship between message relevance, information value, message receiving time, and consumers' permission to receive advertising messages on consumers' acceptance of mobile advertising and subsequent intention to purchase of promoted products using mobile advertising.

The findings of the study indicate the positive relationship between informational value, receiving time and consumer permission in consumers' acceptance of mobile advertising. The present study recommends that marketers should pay attention to drivers and obstacles of mobile advertising as a significant marketing tool that influences brand image, competitiveness, and long-term success.
\end{abstract}

Corresponding author: Mohammed Saleh Salem

Email addresses for corresponding author:m.salem@arabou.edu.sa

First submission received: $7^{\text {th }}$ July 2017

Revised submission received: $1^{\text {st }}$ October 2017

Accepted: $5^{\text {th }}$ February 2018

\section{Introduction}

Rapid developments in mobile means of communication have brought out new communication channels for marketers to reach their customers (Tsang, Ho\& Liang, 2004). Particularly young generation uses mobile phones as a multipurpose means of communication by receiving and sending text messages, graphics, data, music, video etc. These stated features of mobile phones make mobile phones one of the most important means of communication (Jun \& Lee,2007).The growth of the mobile communication market, the profusion of new technologies and their convergence has opened many new opportunities for marketing promotions and advertisements. One of those new modes of advertising is via short message service (SMS). SMS, known as text messaging, is a store-and-forward communication system for the mobile phone (Bamba and Barnes, 2007). Text message services have been hugely popular for interpersonal communication, allowing users of all ages to exchange messages with both social and business contacts (Xuet al. 2003; Dickinger et al. 2004). Xu et al. (2003) identified three consistent success indicators for SMS messaging: (a) the cost-effectiveness and interoperability of the wireless infrastructure; (b) the high penetration of mobile phones; and (c) the relatively low cost of the SMS messaging service. 
Mobile phones are direct marketing tools that enable communication with target groups in any place and at any time and create a bilateral relationship between the marketer and the customers (Barnes \& Scornavacca, 2004; Siavoshi, 2009).

Studies on this new advertising medium indicate that mobile advertising campaigns can generate responses that are as high as $40 \%$, compared with a 3\% response rate through direct mail and $1 \%$ with internet banner ads (Jelassi \& Enders 2004). Along with mobile phone ownership and rapid increase in its use, mobile advertising has emerged as an important communication channel and enabled the rapid adaptation of wireless technologies in marketing strategies (Kolsaker \& Drakatos, 2009; Wong and Tang,2008). The reasons why mobile phones have gained importance in marketing can be stated as follows: customers who own mobile phones always carry their devices with them everywhere, their always being open to communication, one-to-one communication that attracts more attention and the opportunity to have one-to-one audio-visual communication. It is fast and effective for interaction between consumers and advertising companies. Messages can be generally delivered to the consumers without any spatial and temporal constraints. Therefore, consumers can easily be interested in them. In this regard, special services of short messages have been highly successful (Tsang, Ho \& Liang, 2004; Sevtap et al., 2011). Mobile SMS advertising has becoming increasingly important among marketers since it can personalize messages and it is interactive (Wong and Tang, 2008).

Despite the fact that mobile advertising is one of the fast growing marketing tool, there is a limited amount of research having focus on mobile advertising, its acceptance in consumers and subsequent purchase intention of promoted products or services using mobile advertising. Furthermore, very few studies have focused on Saudi Arabian consumers' acceptance of mobile advertising, although the usage of mobile messages is quite high as compared to developed countries.

\section{Literature review \& theoretical framework}

Electronic-marketing (e-marketing) refers to "the achievement of marketing objectives through the use of electronic communications technology" (Chaffey, 2003).E-marketing is often used as a tool of direct marketing, i.e. "Marketing through advertising media that interact directly with consumers, generally calling for the consumer to make a direct response" (Kotler et al., 2002).Mobile marketing or wireless marketing is a subset of e-marketing and is defined by Dickinger et al. (2005) as using a wireless medium to provide consumers with time-and-location-sensitive, personalized information that promotes goods, services and ideas, thereby benefiting all stakeholders". Mobile marketing includes all activities required to communicate with customers through the use of mobile devices in order to promote the selling of products or services and the provision of information about these products and services.

Mobile advertising has typically been categorized into push- and pull-models (Barnes, 2002). In the pull-model campaign, the marketer sends the information requested by the consumer; whereas in the push-model campaign, the marketer takes the initiative to send messages to the consumer. The latter model includes much of SMS advertising and raises the issue of consumers' permission, since it is the marketer that initiates contact and communication. Permission marketing refers to the asking of consumers 'consent to receive commercial messages while giving the individual and opportunity to stop receiving them at any time (Tezinde et al., 2002). This approach can considerably reduce individuals' privacy concerns and can act as a trust-building alternative to more effective information control (Sheehan \& Hoy, 2000).

Barwise and Strong (2002) identify six ways of using SMS for advertising: brand building, special offers, timely media "teasers" competitions, polls/voting, products, services and information requests. Text message ads have been found to boost consumers' inclination to purchase by 36 per cent, which partly explains its growing popularity among marketers (Enpocket, 2005).Bauer et al. (2005) test a model, based on the theory of reasoned action (Ajzen \& Fishbein, 1980), and find that the most important factors that affect attitude toward mobile marketing are: consumers' attitudes toward advertising in general; perceived utility (in terms of information, entertainment, and social aspects); perceived risk (in terms of privacy and data security); consumers' knowledge about the technology; and social norms that impact on consumers' behaviour. Wu and Wang (2005) attempted to examine the drivers to mobile commerce, based on the theory of planned behaviour. They examined perceived risk (e.g. privacy and security issues), cost (e.g. hardware and service fees), compatibility (e.g. with user's existing values, previous experiences and 
needs), and ease of use. However, their model omits to address the social influence that can impact on the decision to acquire mobile devices.

Krishnamurthy (2001) found that the factors affecting consumer willingness to give permission to receive advertisement were: message relevance (e.g. message fit and advertiser attractiveness); monetary benefit (e.g. the incentive); personal information entry/modification cost; message processing cost (e.g. cognitive load in reading messages); and privacy cost (e.g. uncertainty of information misuse). Barwise and Strong (2002) suggested that mobile advertising works best for marketing simple and inexpensive products and services. Since mobile phones are very personal devices, mobile advertising can often be regarded as intrusive, although relevance and added value (e.g., discounts or special offers) can increase consumer acceptance. Bauer et al. (2005) identified entertainment value and information value as the strongest drivers of mobile advertising acceptance. They argued that consumers develop a positive attitude towards mobile advertising - which in turn leads to the behavioral intention to use mobile services - only if mobile advertising messages are creatively designed and entertaining, or if they provide a high information value. Sang, Ho, and Liang (2004) also found that consumers have usually negative attitudes toward mobile advertising except they have specifically consented to receive the advertising messages.

It has been argued that the acceptance of a mobile marketing message is likely to be influenced by the consumer's acceptance of the mobile medium, the relevance of the content, and the context of the marketing message (Heinonen \& Strandvik 2003; Barnes \& Scornavacca 2004; Dickinger et al. 2004; Bauer et al. 2005; Soliman \& Salem 2014). Messages that are short and concise, funny, interactive, entertaining and relevant to the target group usually achieve higher levels of success (Dickinger et al. 2004; Jelassi \& Enders 2004).Barnes and Scornavacca (2004) believed that the three most important variables that could influence consumers' acceptance of mobile advertising are: user permission, wireless service provider control and brand trust.User permission was believed to be the most important variable, as consumers were seen to be fearful of SMS mobile advertising and high levels of spam, as with email marketing. Coined and popularised by Godin (1999), permission marketing is the opposite of traditional interruption marketing. Permission marketing is about building an ongoing relationship of increasing depth with customers by obtaining customer consent to receive information from a company. Permitted messages can be tailored to time, location and personal characteristics, to get closer to the user. In addition to these factors, trust in mobile messages is added as an antecedent to attitude. It is most likely that when the consumers trust in the usefulness of the messages, they will develop a positive attitude. Zhang and Mao (2008) find some contributing results for the significance of trust in increasing behavioural intention to accept mobile advertising. Moreover, trust is shown to affect attitude to electronic channels, new technologies, mobile commerce and mobile advertising (Leppaniemi \& Karjaluoto, 2005; Yang et al., 2006).

According to Leppaniemi \& Karjaluoto (2005), consumer acceptance is one of the highly important issues in mobile marketing and almost 30 percent articles published related to mobile marketing are about acceptance and adoption of mobile marketing (Varnali and Toker, 2010). On the basis of previous studies, Merisavo et al. (2007) propose and validate five types of factors that would influence consumers' acceptance. These are - perceived utility (perceived usefulness, relevance, monetary incentives, entertainment and information value), utilization of contextual information(timely and location-based services), perceived control (permission, opt-out, and filter),perceived sacrifice (risks of losing control, privacy and time, irritation and intrusion)and trust (the operator's and marketer's uses of personal data, and protection of privacy law).Consumers' acceptance of mobile advertising is influenced by factors such as incentives given to the consumer as a reward for their acceptance (Barwize and Strong 2002; Retti et al. 2005; Drossos et al. 2007). It was also found that consumers are willing to accept mobile advertising if the advertising message has relevant information and is of consumers' interest (Tsang et al. 2004; Retti et al. 2005; Bauer et al. 2005).

A widely applied theory within mobile advertising literature, technology acceptance model (TAM), also indicates influence of attitudes on intention to use, and thus to accept a technology (Davis et al., 1989). Previous studies indicate evidence for the relationship between consumer attitudes and consumer intentions, advertising effectiveness (Barwise and Strong, 2002) and acceptance (Bauer et al., 2005; Tsang et al., 2004) within the mobile context. As such, in order for consumers to accept mobile 
advertising, they should first have a positive attitude towards it. Rettie and Brum (2001) further show that even though initial attitudes towards mobile advertising are negative, many consumers are prepared to accept advertising in exchange for promotional offers. Researchers have also validated entertainment, information, emotional and functional values as the most important factors (Bauer et al., 2005). Customers have negative attitudes toward receiving unwanted and unexpected advertisements. Unwanted messages, called spam, damage the acceptance of messages on the side of customers and can have the most negative influence on the user's attitude toward mobile advertising. Therefore, mobile advertising follows the idea of authorized marketing. Tsang et al. (2004) and Noor et al. (2013) state that users are more inclined to ignore advertisements sent without authorization and it has a significant impact on the relationship between consumer attitude and the intention of accepting advertisements. Therefore, asking for authorization of the users results in a positive attitude toward mobile advertising.

Saleem (2013) examined the acceptance of SMS advertising among young Pakistani consumers and revealed that perceived utility and perceived trust are the two major determinants of intentions to use SMS advertising. However, perceived ease of use and subjective norms also play a role in predicting intentions. Almossawi (2014) analyzed the reactions to and perceptions of 247 young mobile users in Bahrain towards mobile advertising. The study found that these young consumers' attitudes towards SMS advertising were determined by five SMS attributes: entertainment value, informativeness, credibility, personalization, and irritation level. Bakar \& Bidin (2014) investigated the relationship between technology acceptance and purchase intention on movie mobile advertising among youth Twitter users in Malaysia. The findings advocated that technology acceptance; use and usefulness in movie mobile advertising contributed significantly towards movie purchase intention among youth. Delafrooz \& Zanjankhah (2015) indicated that Iranian consumers have a positive attitude toward mobile advertising. They also acknowledged that getting consumers' permission enhances their trust and satisfaction with advertisements and subsequent positive attitude towards mobile advertising.

Most of the previous studies in mobile advertising show that there is a positive relationship between consumers' attitude toward mobile advertising and the message content related factors such as message relevance, information value, and message receiving time. Figure 1 illustrates the study framework.

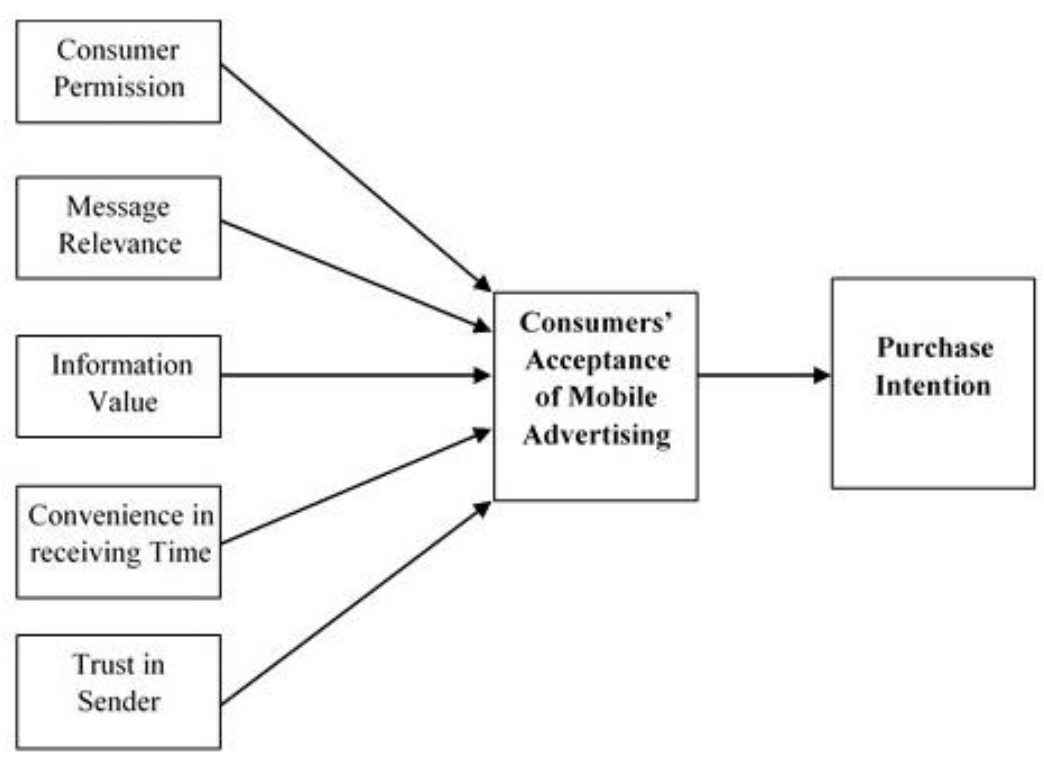

Figure 1: Research Theoretical Framework

\section{Research Objectives}

The mobile phone is one of the most successful innovations in the modern era due to its ease of use and usefulness in communication between people at anytime and anywhere. Mobile messaging is 
often described as a "near-synchronous" communication medium, placing it between a synchronous communication medium such as speech and an asynchronous communication medium such as email (Avrahami and Hudson 2006). The main purpose of this study is twofold. First, the study aims to examine the relationship between message relevance, information value, message receiving time, and consumers' permission to receive advertising messages as independent variables and consumers' acceptance of mobile advertising. Second, this study investigates the effect of consumers' acceptance of mobile advertising on subsequent purchase intention of promoted products or services using mobile advertising.

\section{Research Hypotheses}

$\mathbf{H}_{1}$ : Message relevance is positively associated with consumers' acceptance of mobile advertising.

$\mathbf{H}_{2}$ : Information value is positively associated with consumers' acceptance of mobile advertising.

$\mathbf{H}_{3}$ : Convenience of message receiving time is positively associated with consumers' acceptance of mobile advertising.

$\mathbf{H}_{4}$ : Consumers' trust in the mobile advertiser increase consumers' acceptance of mobile advertising.

$\mathbf{H}_{5}$ : Consumers' permission to receive mobile advertising messages positively affects consumers' acceptance of mobile advertising.

$\mathbf{H}_{6}$ : Consumers' acceptance of mobile advertising positively affects consumers' intention to purchase the promoted products/services.

\section{Research Methodology}

The present research work was Descriptive in nature. Researchers employed Google Forms to create a web-based survey. Weible and Wallace (1998) advocated the applications of newer forms of data collection such as e-mail and web-based survey because of prompt delivery and shorter return times of the survey instrument. Data for the study was collected from prospective respondents located in a major university in Saudi Arabia. 500 e-mail messages were sent to students and staff with the survey link. University students and staff are easy to access and represent the targeted population. We received 225 responses out of the 500 messages sent. Therefore, the response rate was $45 \%$. Out of 225 responses received, a final valid 205 responses being used in this study, excluding 20 responses that were unreliable or insincerely answered.

The existing literature helped in the design of the research instrument and construct related to mobile advertising, consumer acceptance and subsequent purchase intention towards advertised product/service were selected based on studies related. Some questions were then modified by the researchers in order to focus on specific information. The survey questionnaire consisted of two sections. The first section of the questionnaire contained questions to examine surveyed consumers' demographic profile. The second section of the questionnaire was concerned with attributes related to dimensions of mobile advertising, consumers' attitude towards mobile advertising, consumer acceptance of mobile advertising and purchase intention. Respondents were asked to indicate their level of agreement in a fivepoint Likert-scale ranging from 1 (strongly disagree) to 5 (strongly agree). In order to ensure the validity of survey instrument, the initial questionnaire was given to a panel of experts to review its content validity, the precision of its items meaning and to ensure its linkages with the objectives of the study. In order to validate the reliability, the questionnaire was pilot tested using 50 respondents who were considered the representatives of the study population. The value of Cronbach's alpha was found 0.823, which suggested a highly acceptable level of reliability of the questionnaire. The data thus received was systematically arranged, tabulated and analyzed using SPSS and structural equation modeling (SEM) using AMOS. 
Table 1: Definition and Operationalization of Variables

\begin{tabular}{|c|c|c|}
\hline Variable & Definition & Related Studies \\
\hline Message relevance & $\begin{array}{l}\text { The extent to which the advertising message is } \\
\text { related to the consumers' interest. }\end{array}$ & $\begin{array}{l}\text { Retti et al. (2005) } \\
\text { Drossos et al. (2007) }\end{array}$ \\
\hline Information value & $\begin{array}{l}\text { The extent to which the mobile advertising message } \\
\text { contains valuable information from which consumer } \\
\text { can benefit. }\end{array}$ & Tsang et al. (2004) \\
\hline $\begin{array}{l}\text { Convenience of message } \\
\text { receiving time }\end{array}$ & $\begin{array}{l}\text { The most appropriate time to receive the text } \\
\text { message }\end{array}$ & $\begin{array}{l}\text { Heinonen \& Strandvik 2003; } \\
\text { Pura } 2005\end{array}$ \\
\hline $\begin{array}{l}\text { Consumers' trust in } \\
\text { sender }\end{array}$ & $\begin{array}{l}\text { Degree to which consumer rely on advertiser and its } \\
\text { offerings }\end{array}$ & $\begin{array}{c}\text { Merisavo et al. (2007)Zhang \& } \\
\text { Mao (2008) }\end{array}$ \\
\hline Consumers' permission & $\begin{array}{l}\text { Obtaining customer consent to receive information } \\
\text { from a company. }\end{array}$ & Jayawardhena et al. (2009) \\
\hline $\begin{array}{l}\text { Consumers' acceptance of } \\
\text { mobile advertising }\end{array}$ & $\begin{array}{l}\text { Consumer readiness to receive advertising and } \\
\text { promotional message on mobile devices }\end{array}$ & $\begin{array}{l}\text { Bauer et al. (2005) } \\
\text { Merisavo et al. (2007) } \\
\text { Yang et al. (2010) }\end{array}$ \\
\hline Purchase intention & $\begin{array}{l}\text { The willingness of a customer to buy a certain } \\
\text { product or service advertised. }\end{array}$ & $\begin{array}{l}\text { Ajzen\& Fishbein (1980), } \\
\text { Drossos \& Fouskas (2010) }\end{array}$ \\
\hline
\end{tabular}

There were 205 completed responses comprising 41 percent of the initial sample size with the following demographic information: 60 percent of the respondents were males and 40 percent were females. 35 percent of the respondents were between 26-35 years, 29 percent were between 18-25 years, 18 percent were between 36-45 years, 13 percent were between $45-55$ years, and the remaining five percent were above 55 years. Interestingly, 61 percent of respondents completed the survey using their mobile phones, 29 percent filled the survey using computers (desktop or laptop), and only ten percent used a tablet-pc such as (iPad or Galaxy tab). 43 percent of respondents did not prefer any certain type of advertising messages whereas 30 percent preferred multimedia messages and 27 percent preferred text messages.

\section{Data Analysis and Results}

To assess the validity and reliability of the reflective measures (consumer's permission to receive mobile adverting, message relevance, information value, convenience of message receiving time, consumers' trust in sender, consumer's acceptance of mobile advertising, and purchase intention), we used PLS analysis to conduct confirmatory factor analysis (CFA). The composite reliabilities of all multiitem measures all were above the accepted limit of 0.70 . Specifically, the composite reliability scores range from 0.753 for purchase intention to 0.959 for consumers' acceptance of mobile advertising. Consequently, we conclude that the measurement items are robust in terms of their internal consistency and reliability as indexed by the composite reliability. Convergent validity was assessed using average variance extracted (AVE) for all latent constructs that include reflective indicators and factor loading criteria (Fornell and Larcker, 1981). Factor loading ought to be greater than 0.60 and AVE to be larger than the square of its largest correlation with any construct. All reflective measurement constructs used in this study fulfill these requirements. Table 2 shows that factor loading of most items ranged from 0.618 to 0.953 . The values of average variance extracted ranged from 0.251 to 0.745 . Taken together, these results lend sufficient assurance that the reflective measurement model fits the data well. 
Table 2: Measurement items and Validity Assessment

\begin{tabular}{|c|c|c|c|c|}
\hline \multicolumn{2}{|l|}{ Construct } & Standardized & CR & AVE \\
\hline \multirow{3}{*}{$\begin{array}{l}\text { Consumer's permission to receive } \\
\text { mobile advertising }\end{array}$} & $\mathrm{CP} 1$ & 835 & \multirow{3}{*}{.756} & \multirow{3}{*}{.672} \\
\hline & $\mathrm{CP} 2$ & 624 & & \\
\hline & CP 3 & .671 & & \\
\hline \multirow{6}{*}{ Message Relevance } & MR 1 & .879 & \multirow{6}{*}{.926} & \multirow{6}{*}{0.657} \\
\hline & MR 2 & .953 & & \\
\hline & MR 3 & .891 & & \\
\hline & MR 4 & .870 & & \\
\hline & MR 5 & .623 & & \\
\hline & MR 6 & .684 & & \\
\hline \multirow{2}{*}{ Information Value } & IV 1 & .925 & \multirow[b]{2}{*}{.923} & \multirow{2}{*}{0.617} \\
\hline & IV 2 & .926 & & \\
\hline \multirow{2}{*}{$\begin{array}{l}\text { Convenience of Message receiving } \\
\text { time }\end{array}$} & RT 1 & .877 & \multirow{2}{*}{.857} & \multirow{2}{*}{0.697} \\
\hline & RT 2 & .854 & & \\
\hline \multirow{2}{*}{ Consumers' Trust in Sender } & TIS 1 & .854 & \multirow{2}{*}{.881} & \multirow{2}{*}{0.251} \\
\hline & TIS 2 & .920 & & \\
\hline \multirow{4}{*}{$\begin{array}{l}\text { Consumers' acceptance of mobile } \\
\text { advertising }\end{array}$} & ACC 1 & .911 & \multirow{4}{*}{.959} & \multirow{4}{*}{0.643} \\
\hline & ACC 2 & .953 & & \\
\hline & ACC 3 & .935 & & \\
\hline & ACC 4 & .896 & & \\
\hline \multirow{3}{*}{ Purchase Intention } & PI 1 & .810 & \multirow{3}{*}{0.753} & \multirow{3}{*}{.745} \\
\hline & PI 2 & .695 & & \\
\hline & PI 3 & .618 & & \\
\hline
\end{tabular}

$\mathrm{CR}=$ Composite Relaibilty, AVE = Average Variance Extracted

\section{Structural Model}

Two common indicators, path loadings and the variance explained $\left(\mathrm{R}^{2}\right)$, were estimated to assess the quality of the structural model (Chin, 1998). Whereas path loadings demonstrate the strength of relationship between independent and dependent variables, R-square value measures the predictive power of structural models. The bootstrapping procedure was performed, as suggested by Chin (1998), to examine the variance explained $\left(R^{2}\right)$ and the statistical significance of path coefficients $(\beta)$ using t-tests.

All of the $R^{2}$ values for the endogenous constructs exceed the minimum value of 0.2 recommended by Cohen (1998). Moreover, the $\mathrm{R}^{2}$ value for the outcome variable (purchase intention) indicates that the theoretical model proposed explains $9 \%$ of the variance of the construct, which is a satisfactory level of predictability. Moreover, a global fit measure (the GoF index) is calculated by taking the square root of the mean product of the AVE for the latent variables, and the reflective indexes and the mean $\mathrm{R}^{2}$ for the endogenous variables. This index varies between the values of 0 and $1\left(\mathrm{GoF}_{\text {small }}=0.10, \mathrm{GoF}_{\text {medium }}=0.25\right.$, $\mathrm{GoF}_{\text {large }}=0.36$ ). Our model obtained a GoF value of 0.42 , which is above the cut of value of 0.36 for large sizes of GoF. Thus, we ensure our model performs very well compared to the criterion defined above.

\section{Hypothesis Testing}

A re-sampling bootstrapping procedure with 205 samples was performed in order to determine the significance level of the path coefficients proposed in our six hypotheses (Preacher and Hayes 2004). More specifically, we examined (1) the direct association between message relevance (MR) and consumers' acceptance of mobile advertising (H1), (2) the direct association between information value (IV) and consumers' acceptance of mobile advertising (H2), (3) the direct association between convenience of message receiving time (CRT) and consumers' acceptance of mobile advertising (H3), (4) the direct association between consumers' trust in the mobile advertiser (TS) and consumers' acceptance of mobile advertising, (5) the direct association between consumers' permission to receive mobile advertising massages (CP) and consumers' acceptance of mobile advertising, and (6) the direct association between consumers' acceptance of mobile advertising and consumers' intention to purchase (PI). As seen in Figure 
$2, \mathrm{CP}$ has a significant effect on consumers' acceptance of mobile advertising $\left(\beta=0.309^{* * *}, t=5.015\right)$, supporting H5. The results also show that both IV and CRT have significant effects on consumers' acceptance of mobile advertising, $\left(\beta=0.140^{* *}, t=1.908 ; \beta=0.317^{* * *}, t=4.527\right.$ respectively $)$, supporting $\mathrm{H} 2$ and H3. However, the effects of MR and TS on consumers' acceptance of mobile advertising were found not significant $\beta=0.112^{\mathrm{ns}}, t=1.574$ for MR; $\left.\beta=0.077^{\mathrm{ns}}, t=1.305\right)$, not supporting $\mathrm{H} 1$ and $\mathrm{H} 4$. The effect of consumers' acceptance of mobile advertising on purchase intention (PI) was found significant $(\beta=$ $\left.12.624^{* * *}, t=5.015\right)$, supporting H6.

Figure 2: Structural model and t-values

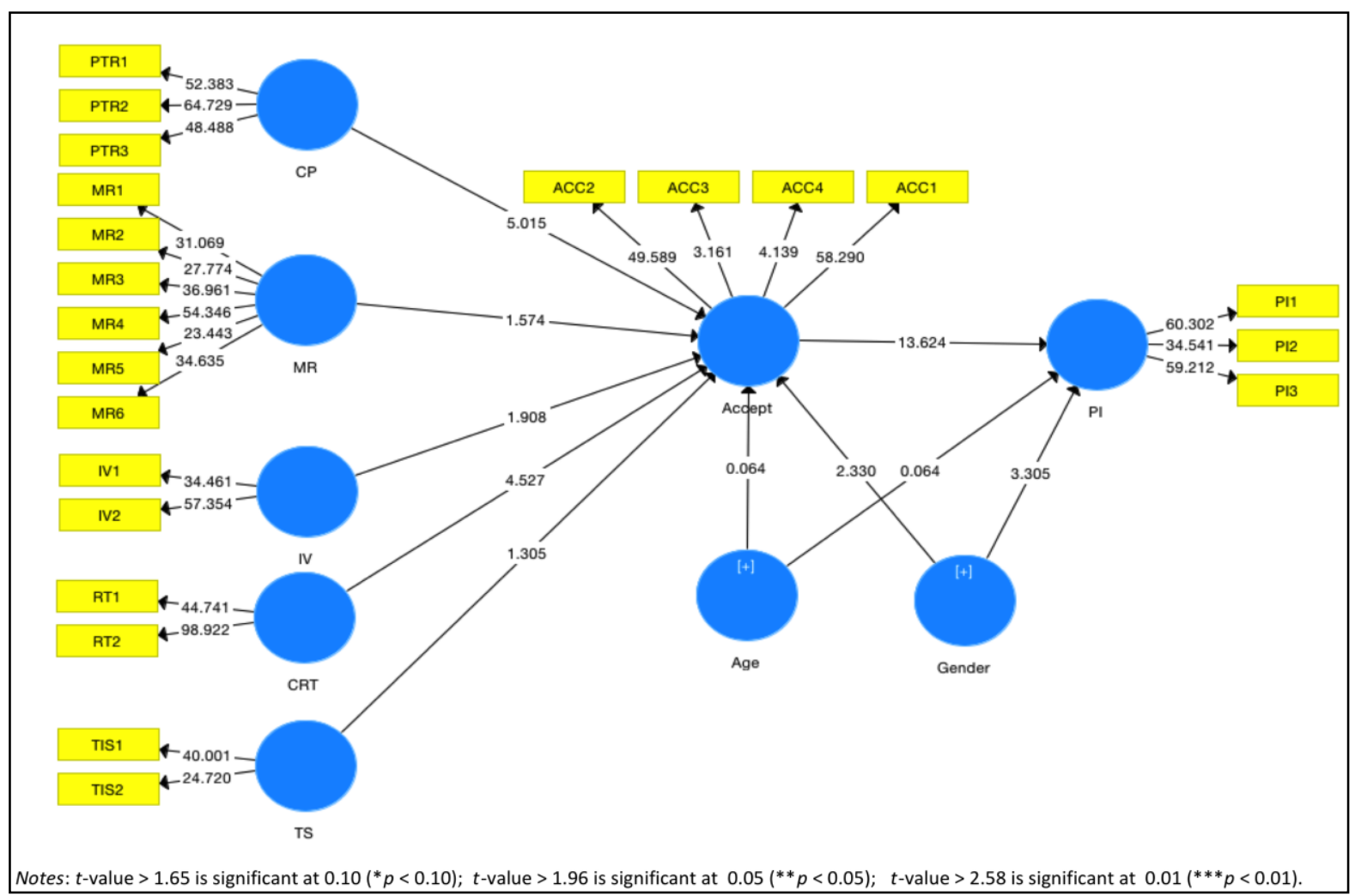

Table 3: Results of Estimates and Hypothesis Testing

\begin{tabular}{|c|l|l|c|c|c|}
\hline $\mathbf{S . N .}$ & Independent Variable & Dependent Variable & $\boldsymbol{\beta}$ & $\mathbf{t}$ & Results \\
\hline $\mathbf{H}_{\mathbf{1}}$ & Message relevance & $\begin{array}{l}\text { Consumers' acceptance of } \\
\text { mobile advertising }\end{array}$ & 0.112 & 1.574 & Not Supported \\
\hline $\mathbf{H}_{\mathbf{2}}$ & Information value & $\begin{array}{l}\text { Consumers' acceptance of } \\
\text { mobile advertising }\end{array}$ & 0.140 & 1.908 & Supported \\
\hline $\mathbf{H}_{\mathbf{3}}$ & $\begin{array}{l}\text { Convenience of message } \\
\text { receiving time }\end{array}$ & $\begin{array}{l}\text { Consumers' acceptance of } \\
\text { mobile advertising }\end{array}$ & 0.317 & 4.527 & Supported \\
\hline $\mathbf{H}_{\mathbf{4}}$ & $\begin{array}{l}\text { Consumers' trust in the } \\
\text { Sender }\end{array}$ & $\begin{array}{l}\text { Consumers' acceptance of } \\
\text { mobile advertising }\end{array}$ & 0.077 & 1.305 & Not Supported \\
\hline $\mathbf{H}_{\mathbf{5}}$ & $\begin{array}{l}\text { Consumers' permission to } \\
\text { receive mobile advertising } \\
\text { messages }\end{array}$ & $\begin{array}{l}\text { Consumers' acceptance of } \\
\text { mobile advertising }\end{array}$ & 0.309 & 5.015 & Supported \\
\hline $\mathbf{H}_{\mathbf{6}}$ & $\begin{array}{l}\text { Consumers' acceptance of } \\
\text { mobile advertising }\end{array}$ & Purchase Intention & 12.624 & 5.015 & Supported \\
\hline
\end{tabular}

\section{Discussion}

This study adds to the growing body of research on consumers' acceptance and mobile advertising. The research reveals a number of implications for practice relating to factors influencing consumers' intention to purchase products or services promoted using mobile advertising. The major 
thrust of this research lies in developing an understanding of the factors that determine consumer acceptance of mobile advertising. This paper demonstrates that consumers are more likely to accept mobile advertising if they develop positive attitudes toward it. The findings also indicate that a number of factors are significant in the forming of consumer attitudes toward mobile advertising. It also offers a perspective regarding the correlation between consumers' accepting of mobile advertisements and their intention to purchase a product or service.

Test statistics do not support the first hypothesis $\left(\mathrm{H}_{1}\right)$ indicating message relevance is not associated with consumers' acceptance of mobile advertising. This proves that consumer acceptance of mobile advertising are more manipulated by other marketing activities such as exploiting the emotional feeling instead of focusing on message relevancy. The study further support the finding which state that under certain conditions attitude correlates with behaviour and is related to a favourable evaluation, emotional feeling and action tendency (Kotler 2000). Marketing activities may lead to either positive or negative reactions in consumers (Robins, 2003).

Hypothesis $\left(\mathrm{H}_{2}\right)$ is supported indicating that the value of the information provided has significant effect on consumers' intention to purchase the products or services advertised. This finding is similar to the studies of Chi, Yeh \& Tsai, (2011), Swait \& Sweeney (2000), Chen \&Quester (2006) and Pura (2005). This might be because mobile advertising messages are more informative and convenient in getting information about the product and service advertised and perceived value can be a differentiation and competitiveness to a company. Additionally, hypothesis $\left(\mathrm{H}_{3}\right)$ relating to the convenience of message receiving time also is supported. It shows that the time the consumers received the message affects their acceptance of mobile advertising. However, factors such as time constraints, the consumer's mood, and product or service suitability may influence the message effectiveness. So, consumers' intention to purchase was significantly affected by the time at which they received the advertisement. It was found that the time at which the consumer received the message have a bearing on their attitude to receiving mobile advertising. It may be that advertisements were received at an inconvenient or annoying time such as when they were in a meeting or discussion important to them.

Contrary to most accepted assumption that trust is a major predictor of consumer's intention to purchase advertised products, the present study surprisingly found that consumers' trust in sender is not related to their acceptance of mobile advertising (H4). This may be the neutral attitude of consumers towards marketing activities of companies or similar types of mobile marketing strategies being adopted by all kinds of companies. This aspect develops the future insight which needs to be researched at length with comprehensive dimensions. Hypothesis $\left(\mathrm{H}_{5}\right)$ indicating the consumers' permission to receive mobile advertising messages affects the consumers' acceptance towards mobile advertising is supported. Permission is beginning of two-way mobile communication between the customer and advertiser. It is not easy to carry out mobile advertisement without clear permission from the customer. Consumers' permission to receive message is about starting of building long-term relationships with customers. The consent, trust and two-way exchange of information help to develop the relationship between the consumer and the advertiser. It was advocated that consumers have a more positive attitude toward mobile advertising after agreeing upon receiving the advertisement. Consumers who did not give permission to companies to send out mobile advertisements tended to ignore and not read the received messages and vice-versa. Mobile advertisements were mostly rated as negative because consumers found the advertisements irritating, given the personal and intimate nature of mobile phones (Tsang et al, 2004). Hypothesis $\left(\mathrm{H}_{6}\right)$ relating to the consumers' acceptance of mobile advertising and subsequent purchase intention is also supported. Therefore, consumer acceptance of mobile advertising was related to their intention to purchase the advertised products or services. This supports the findings of previous research (Merisavo et al. 2007; Nysveen et al. 2005; Pura 2005). Reasons for this may include the information relating to the product or service is of high entertainment and informational value, the appropriate of time of receiving message, a degree of trust between consumer and advertisers, interest in the product being offered, the content and personalization of the message, obtaining consumers' permission before sending the message and an opportunity to visit the advertiser to purchase the product.

As it can be observed from the results, trust and consumers' permission and relevance of message are usefulness and important in the area of mobile marketing. Mobile consumers usually tend to be very 
skeptical and sensitive towards mobile advertising and there is a high possibility that they will reject messages, when they feel that their privacy is invaded or when they feel that they receive a mass message. It is also believed that consumers expect messages that are personal, as well as time and location specific. When messages are created taking consumers 'expectations and needs into consideration, consumers will accept them and even talk about them to other consumers. As a result, future growth in mobile commerce depends on successful personalization of the messages not only in terms of content but also in terms of time and location. The personalization effect is even more important than the consumer's attitude or trust towards mobile advertising, since it enhances also the perceived utility of the messages leading to incremental positive effects.

\section{Conclusion and Future Research}

This research attempted to offer a framework to adequately explain and predict consumers' acceptance towards mobile advertising and purchase intention in a developing country. It is important for managers to recognize the various drivers of, and obstacles to, the acceptance of mobile marketing practices among consumers. The findings from this study suggest several implications to managers involved in the development of mobile marketing strategy and programs within growing mobile markets. The findings of the present study suggest that the acceptance of a message is likely to be influenced by the consumer's acceptance of the mobile medium, the relevance of the content and the context of the marketing communication. Messages that are concise, interactive, entertaining and relevant to the target group usually achieve higher levels of success. The study provides evidence of consumer permission and appropriate time of delivering the message in designing content of mobile advertisements, and, in increasing consumers' acceptance of mobile advertisers. Information value and privacy are essential elements that should be considered and integrated into a mobile advertising campaign to better attract the youth. Saudi Arabia is a huge market, with a substantial young population almost everyone having at least one mobile subscription, constituting a large opportunity for many companies. As a result, the present study focusing on consumers' preferences may shed light to other consumers in less developed and developing countries. Moreover, the use of mobile apps is a common practice among young generations cutting across countries and social classes. Therefore, it is recommended that marketers should pay attention to drivers and obstacles of mobile advertising as a significant marketing tool that influences brand image, competitiveness, and long-term success.

\section{References}

Ajzen, I., \&Fishbein, M. (1980).Understanding attitudes and predicting social behavior, Englewood Cliffs, NJ: Prentice-Hall.

Almossawi, M. (2014). Effectiveness of SMS advertising: a study of young customers in Bahrain. Global Journal of Management and Business Research, 14 (4), 57-71.

Avrahami, D., \& Hudson, S. E. (2006). Communication Characteristics of Instant Messaging: Effects and Predictions of Interpersonal Relationships, Proceedings of the 2006 20th anniversary conference on Computer supported cooperative work, CSCW 2006, November 4-8, 2006, Banff, Alberta, Canada.

Bakar, A.M. \& Bidin, Rosmiza (2014). Technology acceptance and purchase intention towards movie mobile advertising among youth in Malaysia. Procedia - Social and Behavioral Sciences, 130, 558 - 567.

Bamba, F \& Barnes, S.J. (2007). SMS advertising, permission and the consumer: a study. Business Process Management Journal, 13 (6), 815-829.

Barnes, S.J. (2002). Wireless digital advertising: nature and implications. International Journal of Advertising, 21 (3), 399-420.

Barwise, P., \&Strong, C. (2002). Permission-Based Mobile Advertising. Journal of Interactive Marketing, 16(1), 14-24.

Bauer, H. H., Barnes, S. J., Reichardt, T., \&Neumann, M. M. (2005). Driving consumer acceptance of mobile marketing: theoretical framework and empirical study. Journal of Electronic Commerce Research, 6(3), 181-192.

Chaffey, D. (2003). E-Business and E-Commerce Management, Prentice-Hall, London.

Chin, W. (1998). The partial least squares approach to structural equation modeling. In Modern Methods for Business Research, G. Marcoulides, ed., Lawrence Erlbaum Associates Inc., 295-336. 
Chen, S., \& Quester, P. (2006). Modeling store loyalty: Perceived value in market orientation practice. The Journal of Services Marketing, 20, 188-204.

Cohen, J. (1988).Statistical Power Analysis for the Behavioral Sciences, Hillsdale: Lawrence Erlbaum Associates, Inc.

Davis, F. D., Bagozzi, R. P., \& Warshaw, P. R. (1989). User acceptance of computer technology: a comparison of two theoretical models. Management Science, 35(8), 982-1003.

Delafrooz N, Zanjankhah Z. S. (2015). Investigation of psychological factors affecting consumers' intention of accepting mobile advertising. QScience Connect, 6. http://dx.doi.org/10.5339/connect.2015.6

Dickinger, A., Haghirian, P., Murphy, J. \& Scharl, A. (2004). An investigation and conceptual model of SMS marketing. Proceedings of the 37th Hawaii International Conference on System Sciences, Hawaii, January.

Dickinger, A., Scharl, A. \& Murphy, J. (2005). Diffusion and success factors of mobile marketing. Electronic Commerce Research and Applications, 4 (2), 159-73.

Drossos, D. A., \& Fouskas, K. G. (2010). Mobile Advertising: Product involvement and its effect on intention to purchase. Mobile Business and 2010 Ninth Global Mobility Roundtable (ICMB-GMR), 2010 Ninth International Conference on IEEE.

Drossos, D., Giaglis, G. M., Lekakos, G., Kokkinaki, F., \& Stavraki, M. G. (2007). Determinants of Effective SMS Advertising: An Experimental Study. Journal of Interactive Advertising, 7(2), 16-27.

Enpocket (2005). Brand performance of SMS advertising. Available at: www.enpocket.co.uk (accessed on 10 January 2017).

Fornell, C. \& Larcker, D. F. (1981). Structural equation models with unobservable variables and measurement error: Algebra and statistics. Journal of Marketing Research, 18(3), 382-388.

Godin, S. (1999). Permission Marketing: Turning Strangers into Friends, and Friends into Customers. Simon and Schuster, New York, NY.

Heinonen, K. \& Strandvik, T. (2007). Consumer responsiveness to mobile marketing. International Journal of Mobile Communications, 5 (6), 603-617.

Jayawardhena, C., Kuckertz, A., Karjaluoto, H., \& Kautonen, T. (2009). Antecedents to permission based mobile marketing: an initial examination. European Journal of Marketing, 43(3), 473-499.

Jelassi, T. \&Enders, A. (2004). Leveraging wireless technology for mobile advertising. Proceedings of 12th European Conference on Information Systems, Turku, Finland, 14-16 June.

Jun, J.W. \& Lee, S. (2007). Mobile media use and its impact on consumer attitudes toward mobile advertising, International Journal of Mobile Marketing, 2 (1), 50-58.

Kolsaker, A. \& Drakatos, N. (2009). Mobile advertising: the influence of emotional attachment to mobile advices on consumer receptiveness, Journal of Marketing Communications, 15 (4), 267-280.

Kotler, P., Armstrong, G., Saunders, J. \& Wang, V. (2002).Principles of Marketing, European Edition, Prentice-Hall, London.

Kramer, R. M. (1999). Trust and distrust in organizations: emerging perspectives, enduring questions. Annual Review of Psychology, 50(1), 569-598.

Krishnamurthy, S. (2001). A comprehensive analysis of permission marketing. Journal of Computer Mediated Communication, 6 (2). Available at: www.ascusc.org/jcmc/vol6/issue2/krishnamurthy.html (Accessed on $10^{\text {th }}$ February 2017).

Leppaniemi, M. \& Karjaluoto, H. (2005). Factors influencing consumers' willingness to accept mobile advertising: a conceptual model. International Journal of Mobile Communications, 3 (3), 197-213.

Merisavo, M., Kajalo, S., Karjaluoto, H., Virtanen, V., Salmenkivi, S., Raulas, M., \& Leppäniemi, M. (2007). An Empirical Study of the Drivers of Consumer Acceptance of Mobile Advertising. Journal of Interactive Advertising, 7(2), 41-50.

Noor, M.N.M., Sreenivasan, J. \& Ismail, H. (2013). Malaysian consumers' attitude towards mobile advertising, the role of permission and its impact on purchase intention: A structural equation modeling approach. Asian Social Science, 9(5), 135-153.

Nysveen, H., Pedersen, P. E., \& Thorbjørnsen, H. (2005). Intention to use mobile services: antecedents and cross service comparisons. Journal of the Academy of Marketing Science, 33(3), 330-347. 
Preacher, K. J., \&Hayes, A. F. (2004). SPSS and SAS procedures for estimating indirect effects in simple mediation models. Behavior Research Methods, Instruments, and Computers, 36, 717-731.

Pura, Minna (2005). Linking Perceived Value and Loyalty in Location-based Mobile Services. Managing Service Quality, 15 (6), 509-538.

Rettie, R. \& Brum, M. (2001) 'M-commerce: the role of SMS text messages', Proceedings of the Fourth Biennal International Conference on Telecommunications and Information Markets (COTIM 2001), Karlsruhe, Germany, http://www.designinged.com/portfolio/ emedia_plan/M-COM_market.pdf (Accessed on 14 October, 2016).

Saleem Farida. (2013). Acceptance of SMS advertising in young Pakistani consumers. Journal of Business $\mathcal{E}$ Economics, 5 (2), 206-227.

Sevtap U, Ercis A, \& Keser E. (2011). Attitudes towards mobile advertising - A research to determine the differences between the attitudes of youth and adults. Procedia - Social and behavioral sciences, 24, 361377.

Sheehan, K.B. \&Hoy, M.G. (2000). Dimensions of privacy concerns among online consumers. Journal of Public Policy \& Marketing, 19 (1), 62-73.

Siavoshi, MA (2009). The investigation of people's attitude and reaction to receiving advertising messages in information and communication technology age. Journal of Information Technology and Management, 1 (3), 53-68.

Soliman, A., \& Salem, M. S. (2014). Investigating intention to use mobile instant messenger: The influence of sociability, self-expressiveness, and enjoyment. The Journal of American Academy of Business, Cambridge, 19(2), 286-293.

Swait, J., \& Sweeney, J. C. (2000). Perceived value and its impact on choice behavior in a retail setting. Journal of Retailing and Consumer Services, 7(2), 77-88.

Tezinde, T., Smith, B. \& Murphy, J. (2002). Getting permission: exploring factors affecting permission marketing. Journal of Interactive Marketing, 16 (4), 28-36.

Tsang, M. M., Ho, S. C., \& Liang, T. P. (2004). Consumer attitudes toward mobile advertising: An empirical study. International Journal of Electronic Commerce, 8(3), 65-78.

Varnali, K. \& Toker, A. (2010). Mobile marketing research: the-state-of-the-art. International Journal of Information Management, 30, 144-151.

Weible, R., \& Wallace, J. (1998). Cyber research: The impact of the internet on data collection. Marketing Research, 10 (Fall), 19-31.

Wong, Mandy M.T. \& Tang, Esther P.Y. (2008). Consumers' attitudes towards mobile advertising: The role of permission. Review of Business Research, 8 (3), 181-187.

$\mathrm{Wu}, \mathrm{J}$. \& Wang, S. (2005). What drives mobile commerce? An empirical evaluation of the revised technology acceptance model. Information \& Management, 42 (5), 719-729.

$\mathrm{Xu}, \mathrm{H} .$, Teo, H.H. \& Wang, H. (2003).Foundations of SMS commerce success: lessons from SMS messaging and co-opetition. Proceedings of the 36th Hawaii International Conference on System Sciences, Big Island, Hawaii, January.

Yang, H., Zhou, L. \& Liu, H. (2010). A comparative study of American and Chinese young consumers' acceptance of mobile advertising: a structural equation modeling approach. International Journal of Mobile Marketing, 5 (1), 60-78.

Yang, S., Hung, W., Sung, K. \& Farn, C. (2006). Investigating initial trust toward e-tailers from the elaboration likelihood model perspective. Psychology \& Marketing, 23 (5), 429-445.

Zhang, J. \& Mao, E. (2008). Acceptance of mobile SMS advertising among young Chinese consumers. Psychology \& Marketing, 25 (8), 787-805. 